\title{
Structures and Mechanical Properties of Cellulose Filament Spun from Cellulose/Aqueous NaOH Solution System
}

\author{
Chihiro Yamane, Mariko Mori, Masatoshi Saito, \\ and Kunihiko OKaJIMA \\ Fundamental Research Laboratory for Natural \& Synthetic Polymers, \\ Asahi Chemical Industries Co., Ltd., 11-7 Hacchownawate, \\ Takatsuki, Osaka 569, Japan
}

(Received January 25, 1996)

\begin{abstract}
An attempt was made to disclose super-molecular structure and mechanical properties of new cellulose filament prepared from cellulose-aqueous alkali solution system. X-Ray crystallinity index $\chi_{c}(\mathrm{X})$ of the new cellulose filament was far higher than those of other commercial rayons, such as viscose including polynosic and cupro and was slightly lower than the organic spun rayon. The new cellulose filament showed the lowest degree of crystal orientation among these three kinds of cellulose fibers, because of its lowest draft and stretching ratio during the spinning process. In the new filament degree of the intramolecular hydrogen bondings $\left(1-\chi_{\mathrm{am}}\left(\mathrm{C}_{3}\right)\right)$ estimated by ${ }^{13} \mathrm{C}$ NMR method was highly developed. The mechanical loss tangent $(\tan \delta) v s$. temperature $T$ curves of the new filament exhibited $\alpha$ relaxation (from higher temperature side; $\alpha_{2}, \alpha_{\mathrm{sh}}$ ) attributed to micro-Brownian motion of the cellulose chains, two $\beta\left(\beta_{\mathrm{a} 1}, \beta_{\mathrm{a} 2}\right)$, local mode of the chains, and $\gamma$, rotational mode of primary alcohol group at $\mathrm{C}_{6}$ position of pyranose rings, in the regions of $T=250-100^{\circ} \mathrm{C}$ and $-30 \sim-100^{\circ} \mathrm{C}$, and near $-100^{\circ} \mathrm{C}$, respectively. Judging from the co relationships of these relaxation peak temperature $T_{\max }$ to $\chi_{\mathrm{c}}(\mathrm{X})$ and $1-\chi_{\mathrm{am}}\left(\mathrm{C}_{3}\right)$, we concluded that there exist two amorphous regions with well-developed intramolecular hydrogen bonds but less advanced intermolecular hydrogen bonds and vice-versa in the new filament. The results of thermally stimulated currency (TSC) measurements suggested that the hydrophobic interaction among cellulose chains is tightly formed in the region with the well-developed intramolecular hydrogen bonds. In this regard, $\chi_{\text {TSC }}$ peak named here was found to correspond to mechanical relaxation $\alpha_{\text {sh }}$. The tensile strength and elongation of the new filament were comparable to those of the regular viscose rayon. The new filament showed less swelling ratio and low fibrillation nature in water. Woven fabrics made from the filament gave some softness and high abrasion, compared with other commercial ones and were hard to wrinkle.

KEY WORDS Alkali Soluble Cellulose / Filament / Supermolecular Structure / X-Ray Crystallinity / Intramolecular Hydrogen Bonds / Viscoelastic Properties / Mechanical Properties / Woven Fabrics /
\end{abstract}

Authors have already established an improved cellulose dissolving technology (two step slurry method) using so-called steam-exploded pulp with average particle size of $c a .10 \mu \mathrm{m}$ and aqueous (aq) sodium hydroxide $(\mathrm{NaOH})$ solution with total concentration of $c a$. 7.6 $\mathrm{wt} \%,{ }^{1}$ based on the discovery that exploded pulp could be dissolved into aq $\mathrm{NaOH}$ with a specific concentration. $^{2-4}$ In addition, all sulfite pulp, of which the degree of intramolecular hydrogen bond is always lowered by steam-explosion, has been proved to be useful as industrial resource for the above usage. ${ }^{5}$ On the basis of the above technology authors have succeeded in manufacturing a new cellulose filament by establishing the industrially meaningful wet-spinning method (that is, the net-process where no spinning tension generates theoretically), ${ }^{6-8}$ after several efforts on pre-requisite spinning methods for the cellulose/aq $\mathrm{NaOH}$ solution system. ${ }^{9-11}$

It is now highly required to reveal what characteristics of the new cellulose filament possesses, in comparison with other commercial regenerated cellulose fibers. Therefore, in this paper we attempt to disclose the above attention in view of morphology, structure and mechanical properties with special emphasis on mechanical relaxation behavior and thermally stimulated current (TSC) relaxation in amorphous region.

\section{EXPERIMENTAL}

\section{Regenerated Cellulose Fibers}

As commercially available fibers, three kinds of cu- prammonium rayons (Bemberg; Asahi Chemical Co., Ltd.), three kinds of viscose rayons (Asahi Chemical Industries Co., Ltd.), an organic spun rayon (Coutaulds, UK), and a polynosic rayon (Fuji-bou, Japan) were utilized. The new cellulose filament was prepared by the following procedure: A needle leaf sulfite pulp mainly from white spruce (ALAPUL-T, Alaska Pulp Co., Ltd.) was subjected to steam explosion treatment and the resultant refined exploded pulp with degree of polymerization $D P_{\mathrm{v}}=320$ was dissolved in aq $\mathrm{NaOH}$ solution according to the previous procedure. ${ }^{7}$ The obtained cellulose dope exhibited viscosity of 10 poise and was subject to the net process spinning method ${ }^{6-8}$ under the spinning conditions shown in Table I to obtain the new cellulose filament.

\section{Woven Fabrics}

Woven fabrics made of a cuprammonium rayon and a viscose rayon were also supplied by Asahi Chemical Industries Co., Ltd. Woven fabrics from the new cellulose filament were prepared under the conditions show in Table II.

Table I. Spinning condition

\begin{tabular}{|c|c|}
\hline Coagulant & $20 \mathrm{wt} \% \mathrm{H}_{2} \mathrm{SO}_{4},-7^{\circ} \mathrm{C}$ \\
\hline Coagulation-pipe & $5.8 \mathrm{~mm} \phi \times 33 \mathrm{~mm}$ \\
\hline$\Delta V$ & $20 \mathrm{mmin}^{-1}$ \\
\hline Nozzle & $0.05 \mathrm{~mm} \phi, 33 \mathrm{H}$, PCD $3 \mathrm{~mm} \phi$ \\
\hline Draft & 0.38 \\
\hline Spinning speed & $100 \mathrm{mmin}^{-1}$ \\
\hline Draw ratio & 1.25 \\
\hline
\end{tabular}


Table II. Preparation of fabric from new-cellulose filament

\begin{tabular}{|c|c|c|}
\hline Fabric & $\begin{array}{l}\text { Weave pattern } \\
\text { Fabric count Warp } \\
\text { Weft } \\
\text { Air jet loom } \\
\text { Revolving speed }\end{array}$ & $\begin{array}{l}\text { Plain weave } \\
132 \text { yarns/inch } \\
83 \text { yarns/inch } \\
\text { Z-A } 103 \text {, Zudakoma Industry Co., Ltd. } \\
600 \mathrm{rpm}\end{array}$ \\
\hline Dyeing condition & $\begin{array}{l}\text { Pressure of squeeze rolls } \\
\text { Dyes } \\
\text { Dyeing assistants }\end{array}$ & $\begin{array}{l}\text { Open-width dyeing, } 24^{\circ} \mathrm{C} \times 20 \mathrm{~h} \\
5 \mathrm{~kg} \mathrm{~cm}^{-2} \\
\text { Reaction dyes } \\
\mathrm{NaOH}, \mathrm{Na}_{2} \mathrm{CO}_{3} \text {, urea }\end{array}$ \\
\hline Condition of resin finish & $\begin{array}{l}\text { Pressure of squeeze rolls } \\
\text { Dry-cure } \\
\text { Resin } \\
\text { Catalyst } \\
\text { Softening agents }\end{array}$ & $\begin{array}{l}\text { Open-width padding followed by dry-curing } \\
5 \mathrm{~kg} \mathrm{~cm}-2 \\
100^{\circ} \mathrm{C} \times 1 \mathrm{~min}-160^{\circ} \mathrm{C} \times 3 \mathrm{~min} \\
\text { "Yunika resin" } \mathrm{GS}-15(\text { di-methylol di-hydroxy ethylene urea }) \\
\text { "Yunika catalyst" } \mathrm{MC}-109\left(\mathrm{MgCl}_{2}+\text { organic acid }\right) \\
\text { Methylol amide }\end{array}$ \\
\hline
\end{tabular}

\section{Mechanical Property Analysis}

Tensile strength and elongation in dry and wet states, knot strength and elongation, boil shrinkage and Young's modulus were measured according to the testing method for chemical fiber filament (JIS L 1013-1981). Color fastness against wet abrasion and light, Martine Dale abrasion strength (surface abrasion resistance), bending resistance and wrinkle recovery of the woven fabrics were examined according to JIS L 0849-1971, JIS L 0842-1988, JIS L 1096-1990, JIS L 1096-1990A, and JIS L 1059-1992A, respectively.

\section{X-Ray Diffraction Analysis}

$\mathrm{X}$-Ray diffraction patterns of regenerated cellulose fibers were measured by a reflection method and recorded on a X-ray diffraction apparatus with scintillation counter (Rotor Flex Ru-200PL, Rigaku Denki Co., Ltd., Japan). Sample fibers were cut into particle-like size so as to erase the influence from the crystalline orientation of each sample fiber. Crystallinity index $\chi_{\mathrm{c}}$ was estimated by peak areas responsible for (110), (110), and (200) planes, separated with Lorentz--Gaussian peak separation method.

Crystalline orientation parameter $f_{\mathrm{c}}$ of filament bundle was estimated from diffraction strength for azimuthal directions $(\psi)$ by fixing scintillation counter at $2 \theta=20.0^{\circ}$ (corresponding to (110) plane) and by rotating sample bundle to perpendicular direction against incident $\mathrm{X}$-ray. $f_{\mathrm{c}}$ was calculated from the following equation. ${ }^{12}$

$$
f_{\mathrm{c}}=\left\{1-\left(\psi_{1 / 2} / 180\right)\right\} \times 100
$$

$\psi_{1 / 2}$ means half value width (degree) of the diffraction intensity.

\section{CP/MAS ${ }^{13} C$ NMR Analysis}

The degree of break-down in $\mathrm{C}_{3}-\mathrm{O}_{5}^{\prime}$ intramolecular hydrogen bond $\chi_{\mathrm{am}}\left(\mathrm{C}_{3}\right)$ of sample fibers was evaluated according to the previous procedure. ${ }^{13}$ The degree of intramolecular hydrogen bond is defined as $1-\chi_{\mathrm{am}}\left(\mathrm{C}_{3}\right)$. Operating conditions are follows: instrument; FX200 (JEOL); frequency, 50.1 MHz; accumulation, 500; pulse width, $5 \mu \mathrm{s}$, contact time, $2 \mathrm{~ms}$.

Viscoelastic Analysis

The viscoelastic properties (mechanical loss tangent $\delta$ 1040 $\tan \delta$-temperature $T$ curves) for the cellulose fibers with constant denier $(300 \mathrm{~d})$ dried at $105^{\circ} \mathrm{C}$ for $2 \mathrm{~h}$ were recorded on a viscoelastic spectrometer (Model SDM5000, Seiko Densi Co., Ltd., Japan) under the following conditions: frequency, $100 \mathrm{~Hz}$; heating rate, $10^{\circ} \mathrm{C} \mathrm{min}^{-1}$, measuring interval, $1^{\circ} \mathrm{C} \mathrm{min}^{-1}$; sample length, $20 \mathrm{~mm}$; adding amplitude, $16 \mu \mathrm{m}$; initial charge, $1140 \mathrm{~g} \mathrm{~mm}^{-2}$; scanning of temperature, $-150 \sim 350^{\circ} \mathrm{C}$.

\section{Thermally Stimulated Current (TSC) Analysis}

TSC measurements were made using TSC/RMA spectrometer 91000 (Rigaku/Solomat) on the fiber sample aligned between electrodes in sample chamber, in which $\mathrm{He}$ gas is saturated. Global and thermal window measurements were carried out as follows:

Global measurements: Fiber samples were polarized at a given polarizing temperature $T_{\mathrm{p}}\left(=220^{\circ} \mathrm{C}\right)$ by imposing a polarizing field $V_{\mathrm{p}}\left(=800 \mathrm{~V} \mathrm{~mm}^{-1}\right)$ for a given polarizing time $t_{\mathrm{p}}(=2 \mathrm{~min})$ and the samples were frozen under $V_{\mathrm{p}}$ to $-150^{\circ} \mathrm{C}$ so as to quench the polarized state of the polymer molecules. Subsequently, the depolarization of samples was carried out at a depolarizing temperature $T_{\mathrm{d}}\left(=-150^{\circ} \mathrm{C}\right)$ for a depolarizing time $t_{\mathrm{d}}(=2$ min) and the samples were heated at a rate of $7^{\circ} \mathrm{C} \mathrm{min}^{-1}$. TSC curve (depolarized current $J-T$ curve) was obtained by recording $J$ generated on the heating process. In the separated experiment, fiber samples dried at $105^{\circ} \mathrm{C}$ for $5 \mathrm{~h}$ were immersed into hexane and the resulting samples were polarized at $T_{\mathrm{p}}=20^{\circ} \mathrm{C}$, then subjected to the same procedure described above.

Thermal window measurements: This is a technique to polarize a molecular state having a particular relaxation time within a polarizing mechanism which has some distribution in relaxation time. In the present experiment, the polarizing temperature range $(\Delta T=$ $\left.T_{\mathrm{p}}-T_{\mathrm{d}}\right)$ was set to $2^{\circ} \mathrm{C}$. Under a $V_{\mathrm{p}}\left(=800 \mathrm{Vmin}^{-1}\right)$ the polarization at a $T_{\mathrm{p}}$ was made for $2 \mathrm{~min}$ and the sample was depolarized at $T_{\mathrm{d}}=T_{\mathrm{p}}-2^{\circ} \mathrm{C}$ for $t_{\mathrm{d}}=2 \mathrm{~min}$. At this temperature, the most of dipolar molecules having relaxation time less than 2 min deem to be depolarized. Then, the sample was further cooled down to $T_{\mathrm{p}}-50^{\circ} \mathrm{C}$ so that remaining polarized moiety was frozen, and the TSC curve was obtained by heating to $T_{\mathrm{p}}+50^{\circ} \mathrm{C}$ with the heating rate of $7^{\circ} \mathrm{C} \mathrm{min}^{-1}$. This series of procedures were performed at every $5^{\circ} \mathrm{C}$ between $T_{\mathrm{p}}=-10 \sim 80^{\circ} \mathrm{C}$ 
in order to obtain the activation enthalpy $\Delta H$ and activation entropy $\Delta S$ of the relaxations.

Transmission Electron Microscopic (TEM) Observation

Preparation. Fibers were treated with $15 \mathrm{wt} \%$ of aq $\mathrm{NaOH}$ at $0{ }^{\circ} \mathrm{C}$ for $20 \mathrm{~min}$ and washed thoroughly. Enzyme etching: Fibers were treated with $1 \mathrm{wt} \%$ of cellulase aq solution (Onodzuka R-10 derived Trichoderma Viride, Yakult Co., Ltd., Japan) at $50^{\circ} \mathrm{C}$ for a given time at $\mathrm{pH}=4.5$ controlled in acetic acid buffer $(0.1 \mathrm{~N}$ acetic acid $-0.1 N$ sodium acetate $=10: 7, \mathrm{v} / \mathrm{v}$ ).

Ultra-thin film. The etched fibers were capsulated with blend resin (methyl methacrylate--butyl methacrylate $=$ $4: 1, \mathrm{v} / \mathrm{v}$ ) and subject to preparation of ultra-thin film with a $60 \mathrm{~nm}$ of thickness.

TEM observation. Cross section and the section parallel to fiber axis were observed by EX 1200 (JEOL, Japan) operated at an accelerating voltage of $80 \mathrm{kV}$ after carbon spattering at $10^{-6}$ Torr.

\section{RESULTS AND DISCUSSION}

\section{Crystalline and Intramolecular Hydrogen Bond Natures} of New Cellulose Fibers

Table III summarizes the structural parameters of new cellulose fiber and other commercial fibers. $\chi_{c}(X)$ of new cellulose fiber is similar to that of organic spun rayon, being larger than those of polynosic, cuprammonium rayon, and viscose rayons. Similar tendency is also seen for $1-\chi_{\mathrm{am}}\left(\mathrm{C}_{3}\right)$. The peak temperature of $\alpha_{2}$ relaxation $T_{\max \alpha 2}$ of new cellulose fiber is also similar to that of organic spun rayon, being far lower than those of others. Thus, new cellulose fiber is structurally akin to organic spun rayon, rather than cuprammonium rayon and viscose rayon. This feature might come from the dissolving state of cellulose in these solvent: In former two solvents (aq $\mathrm{NaOH}$ and aq $N$-methyl morpholine $N$-oxide) cellulose is molecularly dispersed without forming derivatives or complex ${ }^{2,14}$ but in the later two solvents cellulose is dissolved in the state of complex or a derivative. It is natural to think that the dissolved state of cellulose strongly influences the coagulated state of cellulose. For examples, authors have found that the morphology of regenerated cellulose membranes recovered from its cuprammonium cellulose solution is predominantly determined corresponding to the difference in complex forms caused by various coagulants. ${ }^{15}$ All fibers in Table III are obtained in general by aqueous coagulation systems. Takahashi proposed as crystallization mechanism of regenerated cellulose that (110) plane with hydrophobic nature is first formed and then this plane is piled up resulting in the crystalline lattice. ${ }^{16}$ Since hydroxyl groups in glucopyranose units of cellulose take equatorial positions, then the axial direction is in hydrophobic nature. In the case of aqueous coagulation system, the surface energy of this hydrophobic plane might be diminished so as to facilitate the piling up of glucopyranose rings, favoring the sheet structure of (110) planes. The sheet structure tends to be in principle formed strongly when coagulants which can strongly interact with hydroxyl groups in cellulose such as water are utilized and when cellulose in solvent does not exist as derivative or complex. This might be one of reasons why new cellulose fiber and organic spun rayon show large crystallinity. In fact, X-ray crystallinity of regenerated celluloses obtained by organic solvents such as acetone and toluene has been proved to be very low. ${ }^{17}$

Most considerable structural difference of the new cellulose fiber from others including organic spun rayon

Table III. Structural parameters

\begin{tabular}{|c|c|c|c|c|c|c|c|c|c|c|c|c|c|c|c|c|}
\hline \multirow{3}{*}{ Sample yarn } & \multirow{3}{*}{$\begin{array}{l}\text { Starting } \\
\text { material }\end{array}$} & \multirow{3}{*}{$D P_{\mathrm{v}}$} & \multirow{3}{*}{$\begin{array}{c}\text { Crystal- } \\
\text { linity } \\
\chi_{\mathrm{c}} \\
(\mathrm{X}) / \%\end{array}$} & \multirow{3}{*}{$\begin{array}{c}\text { Orien- } \\
\text { tation } \\
f_{\mathrm{c}} \\
(\mathrm{X}) / \%\end{array}$} & \multirow{3}{*}{$\frac{\begin{array}{c}1-\chi \text { am } \\
\left(\mathrm{C}_{3}\right)\end{array}}{\%}$} & \multicolumn{3}{|c|}{$\alpha_{2}$} & \multicolumn{2}{|c|}{$\beta_{\mathrm{a} 1}$} & \multicolumn{3}{|c|}{$\beta_{\mathrm{a} 2}$} & \multicolumn{3}{|c|}{$\gamma$} \\
\hline & & & & & & $T_{\max }$ & $\tan \delta$ & \multirow{2}{*}{$\begin{array}{c}E^{\prime} \\
\left(10^{9} \mathrm{~Pa}\right)\end{array}$} & $T_{\max }$ & $\tan \delta$ & $T_{\max }$ & $\tan \delta$ & \multirow{2}{*}{$\begin{array}{c}E^{\prime} \\
\left(10^{9} \mathrm{~Pa}\right)\end{array}$} & $T_{\max }$ & $\tan \delta$ & \multirow{2}{*}{$\left(10^{9} \mathrm{~Pa}\right)$} \\
\hline & & & & & & ${ }^{\circ} \mathrm{C}$ & $\max$ & & ${ }^{\circ} \mathrm{C}$ & $\max$ & ${ }^{\circ} \mathrm{C}$ & $\max$ & & ${ }^{\circ} \mathrm{C}$ & $\max$ & \\
\hline $\begin{array}{l}\text { New-cellulosic } \\
\text { filament yarn } \\
\text { (75d/33f) }\end{array}$ & Pulp & 304 & 45.5 & 75 & 42.2 & 240.0 & 0.0667 & 9.5 & -33.1 & 0.0317 & -77.9 & 0.0439 & 27 & -115 & 0.0358 & 36 \\
\hline \multirow{3}{*}{$\begin{array}{l}\text { Viscose conv. }{ }^{\mathrm{a}} \\
\text { Viscose } \mathrm{HSS}^{\mathrm{b}} \\
\text { Viscose } \mathrm{LS}^{\mathrm{c}}\end{array}$} & Pulp & 268 & 29.2 & 86 & 35.0 & 279.6 & 0.0906 & 5.1 & -42 & 0.037 & -60.5 & 0.0362 & 20 & \multicolumn{2}{|c|}{$-117.50 .0288$} & 24 \\
\hline & Pulp & 268 & 22.1 & 84 & 30.9 & 278.7 & 0.0816 & 6.2 & -40.9 & 0.030 & -62.3 & 0.0321 & 23 & \multirow{2}{*}{\multicolumn{2}{|c|}{$\begin{array}{l}-119.30 .0244 \\
-119.90 .0290\end{array}$}} & 30 \\
\hline & Pulp & 268 & 21.5 & 86 & 28.9 & 271.9 & 0.0771 & 6.2 & -43.9 & 0.0290 & -60.0 & 0.0373 & 26 & & & 30.4 \\
\hline Cupro conv. ${ }^{d}$ & $\begin{array}{l}\text { Cotton } \\
\text { Linter }\end{array}$ & 822 & 43.4 & 90 & 41.5 & 256.1 & 0.0777 & 9.1 & - & - & -68.2 & 0.0360 & 30.2 & \multirow{2}{*}{\multicolumn{2}{|c|}{$-116.70 .0269$}} & 37 \\
\hline \multirow{2}{*}{ Cupro HSS $^{c}$} & Cotton & & & & & & & & & & & & & & & \\
\hline & Linter & 822 & 40.9 & 89 & & 245.8 & 0.0685 & 13 & -37.7 & 0.0277 & -80.1 & 0.0381 & 36 & \multicolumn{2}{|c|}{$-120.40 .0297$} & 42 \\
\hline Cupro LS ${ }^{f}$ & Linter & 822 & 38.2 & 91 & 36.7 & 249.8 & 0.0703 & 12 & -46.49 & 0.0362 & -76.5 & 0.0435 & 30 & \multicolumn{2}{|c|}{$-118.60 .0319$} & 38 \\
\hline $\begin{array}{l}\text { Organic spun } \\
\text { rayong }^{\mathrm{g}} \text { staple }\end{array}$ & Pulp & 594 & 45.9 & 91 & 41.0 & 240.2 & 0.0561 & 19 & -34.21 & 0.0277 & -67.4 & 0.0327 & 40 & -117.6 & 0.0230 & 47 \\
\hline $\begin{array}{l}\text { Polynosic } \\
\text { Fujibou }\end{array}$ & Pulp & 506 & 43.8 & 90 & 40.8 & 250.8 & 0.0686 & 21 & -40.35 & 50.05 & -69.0 & 0.0560 & 50.5 & - & & \\
\hline
\end{tabular}

${ }^{a}$ Viscose rayon filament, conventional spinning, 75 denier $/ 26$ filaments. ${ }^{\mathrm{b}}$ Viscose rayon filament, high speed spinning, 75 denier/33 filaments. ${ }^{c}$ Viscose rayon filament, low speed spinning, 75 denier $/ 33$ filaments. ${ }^{\mathrm{d}}$ Cuprammonium rayon fiament, conventional spinning, 75 denier $/ 45$ filaments. ${ }^{\mathrm{e}}$ Cuprammonium rayon fiament, high speed spinning, 75 denier $/ 54$ filaments. ${ }^{\mathrm{f}}$ Cuprammonium rayon filament, low speed spinning, 75 denier $/ 45$ filamets. ${ }^{\mathrm{g}} 1.5$ denier. 

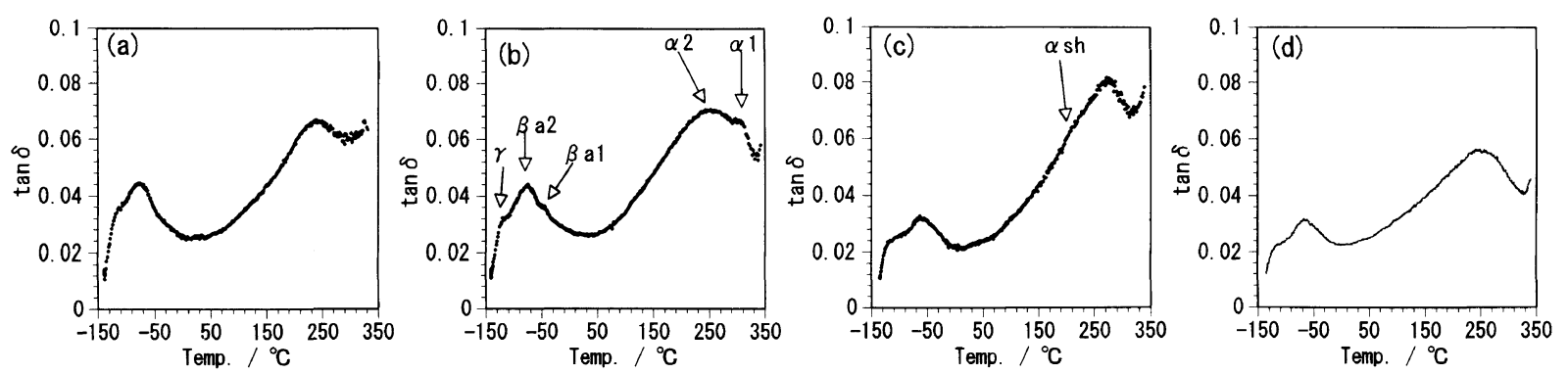

Figure 1. Temperature dependence of $\tan \delta$ for regenerated cellulose fibers: (a), new-cellulose filament yarn; (b), cupro LS; (c), viscose HSS; (d), organic spun rayon.

is crystalline orientation $f_{\mathfrak{c}}$, being far lower than those for organic spun rayon, cuprammonium rayon and polynosics. This feature is clearly reasoned by the difference in draft or stretching imposed during each fiber spinning.

The draft and stretching on new cellulose filament is less than 1 and 1.25 , respectively, which are both equivalent to or smaller than those for viscose rayon. The draft on organic spun rayon and cuprammonium rayon is larger than 10 and 100 , respectively. ${ }^{18,19}$ For organic spun rayon, liquid crystalline nature or flow birefringent nature is also influenced. Even for the present cellulose/aq $\mathrm{NaOH}$ solution system, if the coagulant with stronger dehydration power such as $65 \mathrm{wt} \%$ aq sulfuric acid is used, $f_{\mathrm{c}}$ might increase by dehydrationorientation principle. ${ }^{6}$

\section{Mechanical Relaxation Nature of New Cellulose Fiber}

Figure 1 shows $\tan \delta-T$ curves of the typical regenerated cellulose fibers dried at $105^{\circ} \mathrm{C}$ for $2 \mathrm{~h}$. Manabe et $a l .{ }^{20}$ studied the mechanical relaxation behavior of regenerated cellulose in the temperature range of 280 $600 \mathrm{~K}$ mostly at frequency of $110 \mathrm{~Hz}$, and found three major relaxations $\alpha_{3}$ (at 303-323 K), $\alpha_{2}$ (at 413-563 K) and $\alpha_{1}$ (at 558-578 K) after their terminology, attributing them as the cooperative motion of absorbed water and segments without hydrogen bondings, the micro-Brownian motion of segments with moderately developed hydrogen bondings (split into two absorptions depending on packing density) and the microBrownian motion of segment with strong hydrogen bondings. They also reported a relaxation $\alpha_{\mathrm{sh}}$ seen at $388-473 \mathrm{~K}$ which was said to be only visible for the samples with higher crystallinity.

They also demonstrated that water molecules penetrate into loosely packed molecular chains and act as plasticizer, causing all absorptions observed at dry state to appear at lower temperature side. Regarding $\beta$ relaxation, Manabe et al. ${ }^{21}$ very recently reported that the relaxation region is composed of two components at $-60\left(\beta_{\mathrm{a} 1}\right)$ and $-90^{\circ} \mathrm{C}\left(\beta_{\mathrm{a} 2}\right)$ of which latter peak disappears by treatment of cellulose with organic solvent. Authors also demonstrated that $\beta_{\mathrm{a} 2}$ relaxation peak tends to become small when the regenerated cellulose membranes are prepared with organic solvent coagulants although not exclusive. ${ }^{17} \gamma$ Relaxation observed in the lowest temperature region has been attributed to rotational motion of primary alcohol at $\mathrm{C}_{6}$ position around $\mathrm{C}_{5}-\mathrm{C}_{6}$ axis. ${ }^{22}$ Assignments after Manabe's terminology are given on typical peaks on the $\tan \delta-T$ curves in Figure 1042
1. All relaxation peaks might be visible for all samples although $\alpha_{1}$ and $\beta_{\mathrm{a} 2}$ are clearly observed for cuprammonium rayon. In $\alpha_{\mathrm{sh}}$ temperature region pointed out by Manabe et al., ${ }^{20}$ at least one or two peaks are observed for all fibers. $\alpha_{\mathrm{sh}}$ will be discussed later in connection with TSC relaxation. $\alpha_{\mathrm{H}_{2} \mathrm{O}}$ is also slightly visible for all fibers owing to very low content of water in fibers. The typical mechanical relaxation parameters are also collected in Table III. For the relaxation peak temperature of $T_{\max \beta a 1}, T_{\max \gamma}$, and the peak $\tan \delta$ values of $\tan \delta_{\max \beta \mathrm{a} 2}, \tan \delta_{\max \gamma}$, the new fiber is the highest levels of these values. Contrary to this, for $T_{\max \alpha 2}, T_{\max \beta a 2}$, $\tan \delta_{\max \alpha 2}$, and $\tan \delta_{\max \beta a 1}$, the new fiber is the lowest levels.

$T_{\max \alpha 2}$ of new cellulose fiber is in the same range to that of organic spun rayon and $T_{\max \beta a 1}$ gives similar tendency for new cellulose and organic spun rayon although its order among sample fibers is just reversed to that for $T_{\max \alpha 2}$. The corresponding $\tan \delta_{\max }$ values for the two fibers also prove to give similar tendency but their order among sample fibers are similar, different from the $T_{\max \alpha 2}-T_{\max \beta a 1}$ relation. These facts and the results shown in the first section confirm that in general the new cellulose fiber and organic spun rayon have some structural similarity. However, a close inspection reveals that especially $T_{\max \gamma}$ and $\tan \delta_{\max \gamma}$ are quite different between the above two fibers, like as $f_{\mathrm{c}}$ for the two fibers. This inevitably leads to a conclusion that $\gamma$ relaxation is influenced by the manner of molecular orientation in part.

Figure 2 shows the crystallinity $\chi_{\mathrm{c}}$ dependence of $T_{\max }$ for $\alpha_{2}, \beta_{\mathrm{a} 2}, \beta_{\mathrm{a} 1}$ and $\gamma$ relaxation. Here, data points for new cellulose fiber and organic spun rayon are symbolized as - and $\boldsymbol{\Lambda}$, respectively. $T_{\max }$ for $\alpha_{2}$ and $\beta_{\mathrm{a} 2}$ decrease and $\beta_{\mathrm{a} 1}$ and $\gamma$ increase with an increase in $\chi_{\mathrm{c}}$. Note that $T_{\max }$ for $\alpha_{2}$ and $\beta_{\mathrm{a} 2}$ for new cellulose fiber are in the lowest level contrary to $T_{\max }$ for $\beta_{\mathrm{a} 1}$ and $\gamma$ which are in the highest level. The above results about $T_{\max \alpha 2}$ are just the reverse for Manabe's report, ${ }^{20}$ where $T_{\max \alpha 2}$ is said to increase with an increase in $\chi_{c}$ due to rearrangement of molecular chains in amorphous region induced by the heat treatment on cellulose fibers. It is natural to consider that the crystallization mechanism by heat treatment be different from that caused by phase transformation, for example, the change in solution state to solid state through coagulation procedure. In this regard, Schelton and Imai et al. reported that the crystallization of polymer melts by lowering in temperature does not accompany the considerable change in whole morphology of molecular chains. ${ }^{23-25}$ This is explained as that 

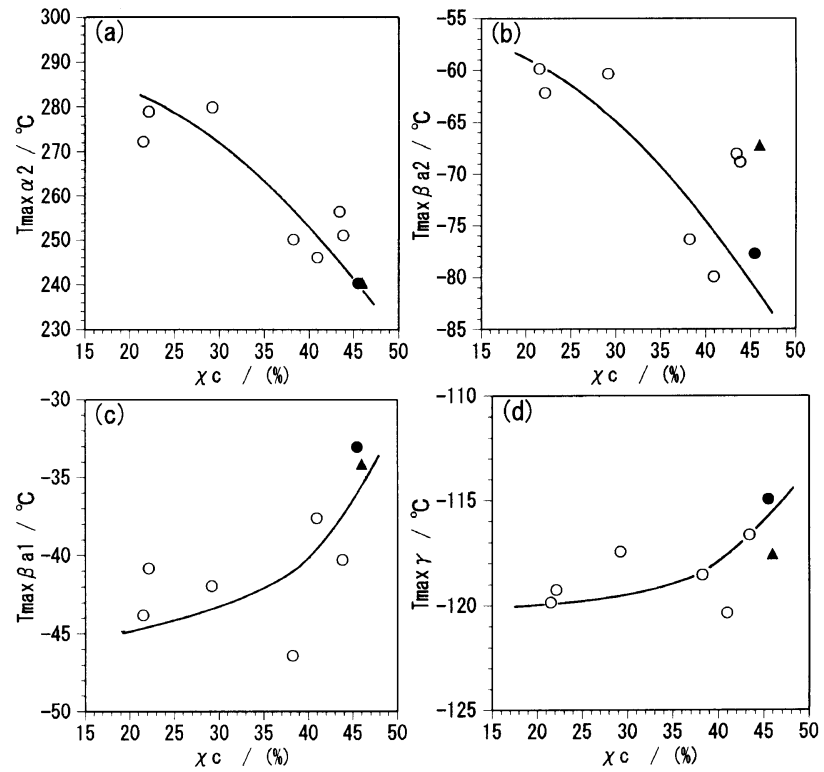

Figure 2. Crystallinity $\left(\chi_{\mathrm{c}}(\mathrm{X})\right)$ dependence on peak temperature $\left(T_{\max }\right)$ : (a), $\alpha_{2}$ relaxation; (b), $\beta_{\mathrm{a} 2}$ relaxation; (c), $\beta_{\mathrm{a} 1}$ relaxation; $(\mathrm{d}), \gamma$ relaxation; $\boldsymbol{O}$, new-cellulose filament; $\boldsymbol{\Lambda}$, organic spun rayon.

crystallization rate is far faster than that of disintegration of molecular chain from the original state of molecular entanglement. ${ }^{26}$ This means that partial crystallization might exclude some strain to microcrystalline intervals leading to some long periodicity of alternative arrangement of crystalline and amorphous region. ${ }^{27-29}$ Therefore, the present results could be explained in part by that the strains excluded into amorphous region makes molecular order more random when $\chi_{\mathrm{c}}$ is larger, leading to lower shift of $T_{\max \alpha 2}$. Note that larger $\chi_{\mathrm{c}}$ corresponds to especially higher intermolecular hydrogen bonding. The above results indicate that amorphous region of new cellulose fiber contains much strain of molecular chains. This in turn suggests that new cellulose fiber could be improved regarding molecular ordering by after treatment such as steam treatment as will be described later.

Figure 3 shows the crystallinity $\chi_{\mathrm{c}}$ dependence of $\tan \delta_{\max }$ for $\alpha_{2}, \beta_{\mathrm{a} 2}, \beta_{\mathrm{a} 1}$, and $\gamma$ relaxation. The data are widely scattered but $\tan \delta_{\max }$ for $\alpha_{2}$ tends to decrease and $\beta_{\mathrm{a} 2}, \beta_{\mathrm{a} 1}$, and $\gamma$ tend to increase with an increase in $\chi_{\mathrm{c}}$. The almost similar relation as obtained for $T_{\max }-\chi_{\mathrm{c}}$ relations are observed, except for $\beta_{\mathrm{a} 2}$, of which $\tan \delta_{\max }$ tends to increase with an increase in $\chi_{\mathrm{c}}$. Manabe et al reported that there are four or five kinds of mechanical absorptions originated from micro-Brownian movement of molecular chains in amorphous phase. ${ }^{20}$ There seems to be at least three regions different in the molecular packing condition in amorphous phase. One is the region where both $T_{\max }$ and $\tan \delta_{\max }$ are positively related to $\chi_{\mathrm{c}}$, another is the region where both $T_{\max }$ and $\tan \delta_{\max }$ are negatively related to $\chi_{c}$, and the other is the region where $T_{\max }$ is negatively but $\tan \delta_{\max }$ is positively related to $\chi_{\mathrm{c}}$.

Figure 4 shows the relations between $T_{\max }$ for each relaxation and $1-\chi_{\mathrm{am}}\left(\mathrm{C}_{3}\right) . T_{\max \alpha 2}$ and $T_{\max \beta \mathrm{a} 2}$ tend to decrease with an increase in $1-\chi_{\mathrm{am}}\left(\mathrm{C}_{3}\right)$, indicating that these two relaxations contain information on intermolecular hydrogen bonding because $1-\chi_{\mathrm{am}}\left(\mathrm{C}_{3}\right)$ gives
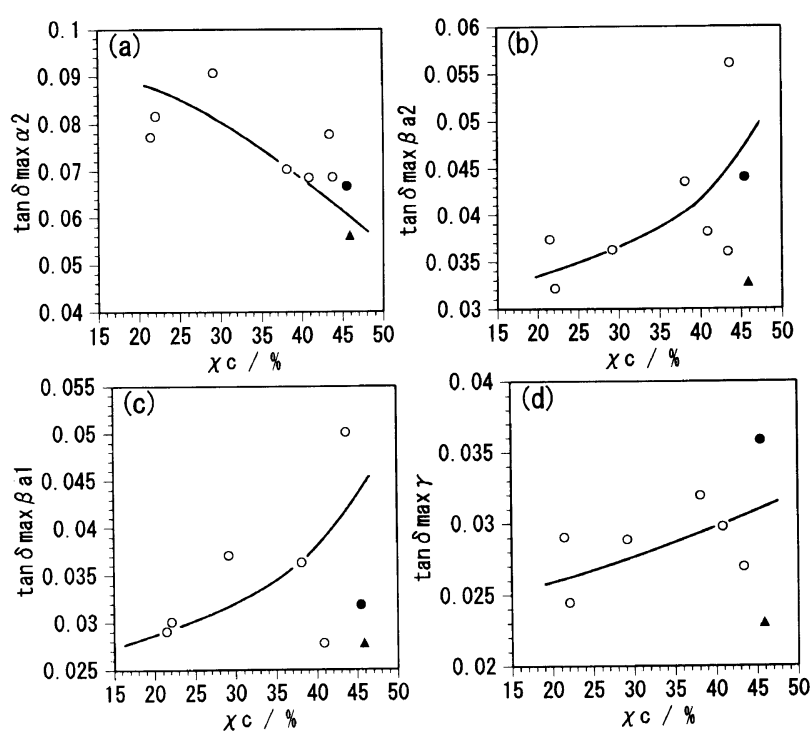

Figure 3. Crystallinity $\left(\chi_{c}(\mathrm{X})\right)$ dependence on peak intensity $\left(\tan \delta_{\max }\right):(\mathrm{a}), \alpha_{2}$ relaxation; (b), $\beta_{\mathrm{a} 2}$ relaxation; (c), $\beta_{\mathrm{a} 1}$ relaxation; (d), $\gamma$ relaxation; $\boldsymbol{O}$, new-cellulose filament; $\boldsymbol{\Delta}$, organic spun rayon.
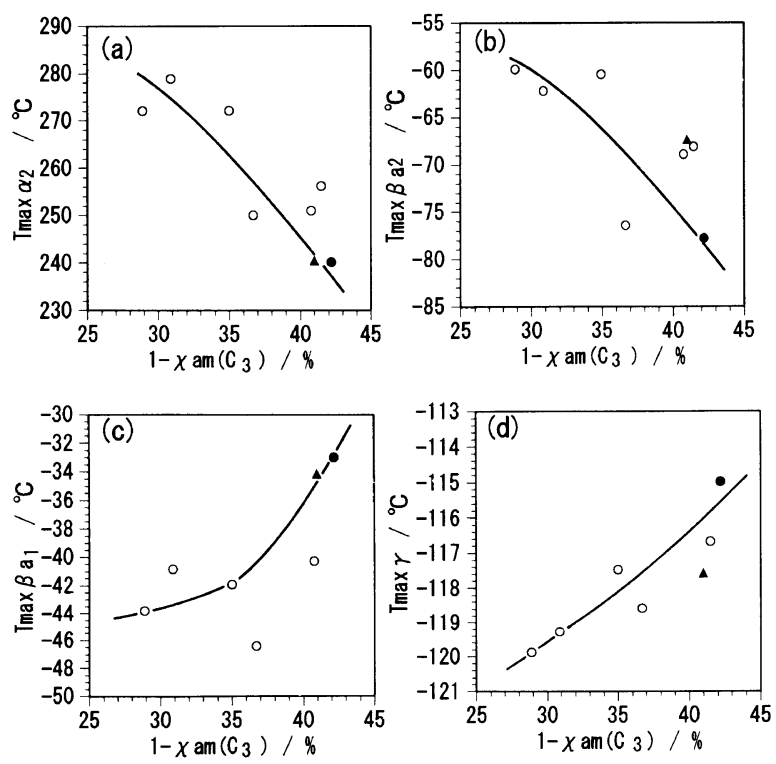

Figure 4. Relationship between degree of intra-molecular hydrogen bonding $\left(1-\chi_{\mathrm{am}}\left(\mathrm{C}_{3}\right)\right)$ and peak temperature $\left(T_{\max }\right)$ for $\alpha_{2}$ relaxation (a), $\beta_{\mathrm{a} 2}$ (b), $\beta_{\mathrm{a} 1}$ (c), and $\gamma$ (d); $\boldsymbol{\bigcirc}$, new-cellulose filament; $\boldsymbol{\Delta}$, organic spun rayon.

information on intramolecular hydrogen bond $\left(\mathrm{C}_{3}-\mathrm{O}_{5}^{\prime}\right)$ for both crystalline and amorphous regions. $T_{\max \beta 1}$ and $T_{\max \gamma}$ tend to give the reversed result and especially the correlation between $T_{\max \gamma}$ and $1-\chi_{\mathrm{am}}\left(\mathrm{C}_{3}\right)$ is superior, suggesting that these relaxations are directly related to intramolecular hydrogen bonding. It is interesting that $\beta_{\mathrm{a} 1}$ and $\beta_{\mathrm{a} 2}$ relaxations give different information regarding hydrogen bonding.

Figure 5 shows the relations between $\tan \delta_{\max }$ for each relaxation and $1-\chi_{\mathrm{am}}\left(\mathrm{C}_{3}\right)$. The data are widely scattered but the almost similar relation as obtained for $T_{\max }-\left(1-\chi_{\mathrm{am}}\left(\mathrm{C}_{3}\right)\right)$ relations are observed, except for $\beta_{\mathrm{a} 2}$, of which $\tan \delta_{\max }$ tends to increase with an increase in $1-\chi_{\mathrm{am}}\left(\mathrm{C}_{3}\right)$. As was described before, there are at least three regions in amorphous phase. The region assigned by $\beta_{\mathrm{a} 2}$ is supposed to have highly-developed inter- 

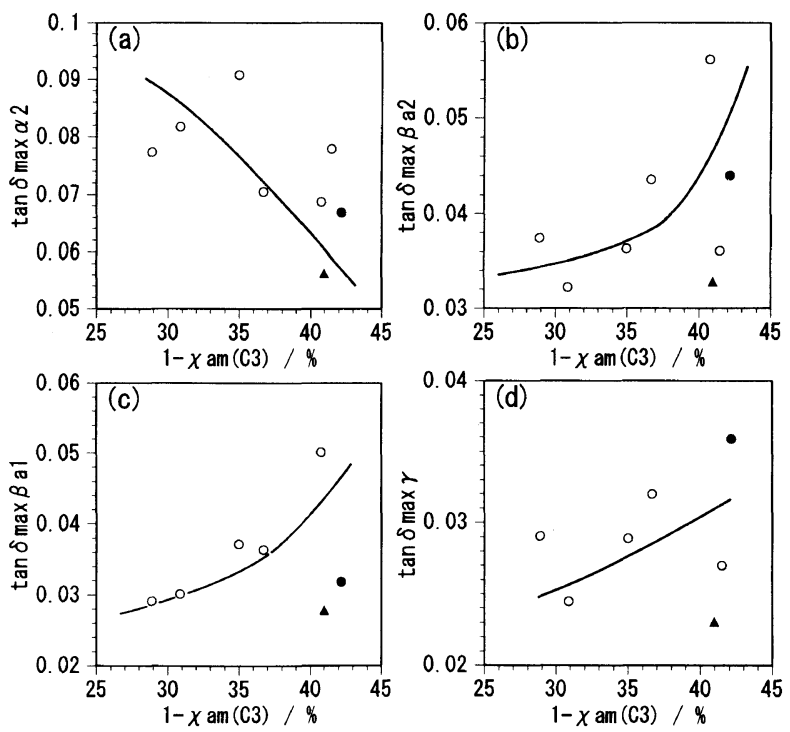

Figure 5. Relationship between degree of intra-molecular hydrogen bonding $\left(1-\chi_{\mathrm{am}}\left(\mathrm{C}_{3}\right)\right)$ and peak intensity $\left(\tan \beta_{\max }\right)$ for $\alpha_{2}$ relaxation (a), $\beta_{\mathrm{a} 2}$ (b), $\beta_{\mathrm{a} 1}$ (c), and $\gamma$ (d); , new-cellulose filament; $\boldsymbol{\Delta}$, organic spun rayon.

molecular hydrogen bonding and have relatively weak hydrophobic interaction by piling up of glucopyranose rings because $\beta_{\mathrm{a} 2}$ relaxation peak disappears by organic solvent treatment ${ }^{21}$ and tends to become small in the case of organic solvent coagulation. ${ }^{17}$

Thus, new cellulose fiber is characterized to have higher intramolecular hydrogen bonding with lower intermolecular hydrogen bonding in its amorphous region. Such regenerated fiber is possible to assume the existence of plane-lattice or sheet like structures in amorphous region, proposed by Hayashi et $a .^{30}$ and Hermans. ${ }^{31}$ For example, (110) sheet itself is formed with hydrophobic interaction by piling up of glucopyranose rings and then if such structure is assumed in amorphous structure the amorphous region might be composed of highly developed intramolecular hydrogen bonding and immature intermolecular hydrogen bonding. The existence of such sheet like structure might be affirmed by the structure forming mechanism proposed by Takahashi ${ }^{16}$ and by the result demonstrated by authors that the structural change induced by water takes place in the perpendicular direction to (110) plane. $^{17}$

\section{TSC Relaxation Nature of New Cellulose Fiber}

As was described in the former section, several $\alpha_{\text {sh }}$ relaxations are visible on $\tan \delta-T$ curves although not so clear. This will be more clearly separable on TSC relaxation curves. In Figure 6, TSC- $T$ curves for typical regenerated fibers dried more completely are shown. Main relaxation peaks are observed around $-126^{\circ} \mathrm{C}$ and -10 to $80^{\circ} \mathrm{C}$. Sawatari ${ }^{32-34}$ has observed for cellophane TSC peaks at $-126^{\circ} \mathrm{C},-70^{\circ} \mathrm{C}$, and $50^{\circ} \mathrm{C}$ and we tentatively name these peaks as $\chi_{\mathrm{TSC}}, \beta_{\mathrm{TSC}}$, and $\gamma_{\text {TSC }}$ from higher temperature. In the present case $\chi_{\text {TSC }}$ and $\gamma_{\text {TSC }}$ seem to be observed but, $\beta_{\text {TSC }}$ peak is not observed around $-70^{\circ} \mathrm{C}$ due to no existence of water in fibers, as was confirmed hithertofore. ${ }^{32,35}$ We can recognize at least two $\chi_{\text {TSC }}$ peaks for fibers except for cu-

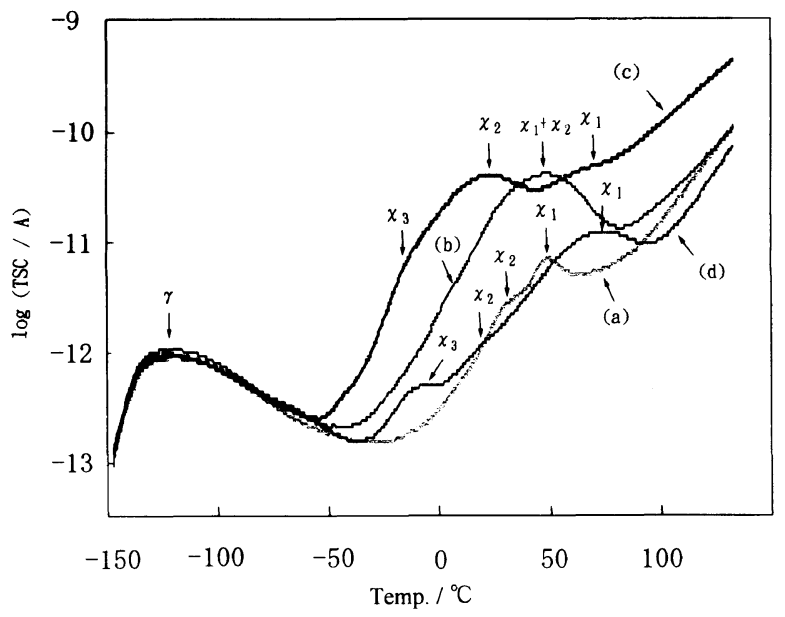

Figure 6. Thermally stimulated current (TSC) spectra of Cellulose fiber at the dry condition: (a), new-cellulose filament yarn; (b), cupro LS; (c), viscose HSS; (d), organic spun rayon.

pramonium rayon. The new cellulose fiber and organic spun rayon give two peaks, viscose rayon gives three peaks and cuprammonium seems to give one peak. These peaks are termed as $\chi_{i \mathrm{TSC}}(i=1,2,3)$ from higher temperature for viscose rayon as standard, as shown in the figure. The peak appearance is quite different from fibers to fibers. One peak for cuprammonium rayon is situated just between $\chi_{1 \mathrm{TSC}}$ and $\chi_{2 \mathrm{TSC}}$ for viscose rayon, then termed as $\chi_{1 \mathrm{TSC}}+\chi_{2 \mathrm{TSC}}$. Organic spun rayon exhibits three peaks at almost similar temperatures as observed for viscose rayon, although the intensity of $\chi_{2 \mathrm{TSC}}$ is far lowered. For the new cellulose fiber two peaks are observed in the temperature regions for $\chi_{1 \mathrm{TSC}}+\chi_{2 \mathrm{TSC}}$, and $\chi_{2 \text { TsC }}$. The observation is quite comparative for $\alpha_{\text {sh }}$. Thermal window TSC analysis for cuprammonium rayon from $-10^{\circ} \mathrm{C}$ to $80^{\circ} \mathrm{C}$ gave the activation enthalpy $\Delta H=121 \mathrm{~kJ} \mathrm{~mol}^{-1}$, the activation entropy $\Delta S=188$ $\mathrm{J} \mathrm{mol}^{-1} \mathrm{~K}^{-1}$ for $-10^{\circ} \mathrm{C}$, and $\Delta H=92 \mathrm{~kJ} \mathrm{~mol}^{-1}$, and $\Delta S=8 \mathrm{~J} \mathrm{~mol}^{-1} \mathrm{~K}^{-1}$ for $80^{\circ} \mathrm{C}$. Combination of these values and the Eyring's relation, ${ }^{36}$ shown eq 2 , revealed that TSC peak at $-10^{\circ} \mathrm{C}$ and $80^{\circ} \mathrm{C}$ corresponds to mechanical relaxation at $47^{\circ} \mathrm{C}$ and $181^{\circ} \mathrm{C}$ respectively at $100 \mathrm{~Hz}$, suggesting that $\chi_{\text {TsC }}$ relaxation corresponds to mechanical relaxation $\alpha_{\text {sh }}$.

$$
\ln (1 / 2 \pi f)+\ln \left(\kappa T_{\max } / h\right)=\Delta H / R T_{\max }-\Delta S / R
$$

Here, $\kappa$ is Boltzmann constant; $R$, the gas constant; $h$, Plank constant.

This is a first demonstration to relate $\chi_{\text {TSC }}$ relaxation with a mechanical relaxation although Sawatari has insisted that the corresponding mechanical relaxation for $\chi_{\text {TSC }}$ has not been observed. ${ }^{32}$

Although not shown here, $\alpha_{\mathrm{sh}}$ for viscose rayons was proved to well correlate positively with $1-\chi_{\mathrm{am}}\left(\mathrm{C}_{3}\right)$, indicating that $\chi_{\text {TSC }}$, hence $\alpha_{\text {sh }}$, might correspond to segmental motion associated with intramolecular hydrogen bond. It is important to note that this relaxation is widely distributed probably owing to other molecular packing states.

Figure 7 shows the TSC- $T$ curves for the dried new cellulose fiber (original) and the hexane-treated new cellulose fiber. Obviously, the hexane-treatment brought about the merging of the original two $\chi_{\text {TSC }}$ peaks ap- 
peared around $50^{\circ} \mathrm{C}$ into one peak and shifted the peak temperature to far lower temperature side $\left(-10^{\circ} \mathrm{C}\right)$. This clearly indicates that the relaxation is closely related to hydrophobic domain in amorphous region. As was described before, this hydrophobic domain might be represented by the sheet structure such as (110) planelike structure. In the case of new cellulose fiber, $\chi_{\mathrm{TSC}}$, hence $\alpha_{\mathrm{sh}}$, might be attributed to micro-Brownian motion of main chains within (1 $1 \overline{1} 0)$ plane like structure, judging from $\Delta H$ for $\chi_{\mathrm{TSC}}$.

On the one hand, $\gamma_{\text {TSC }}$ slightly shift to higher temperature side by hexane treatment. Since the peak temperature for mechanical $\beta_{\mathrm{a} 2}$ relaxation shifts to higher temperature side accompanying the decrease in its intensity when the regenerated cellulose membranes are prepared using organic solvent as coagulant, there is

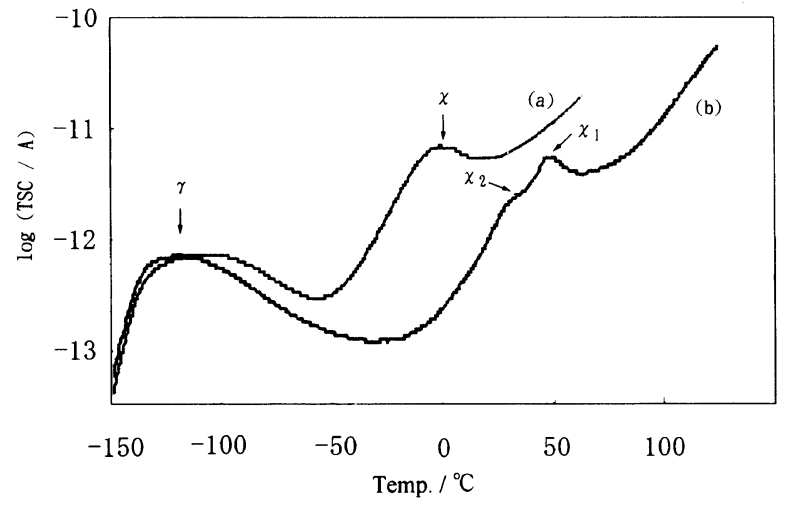

Figure 7. Thermally stimulated current (TSC) spectra of newcellulose filament in the environment with hexane and dry condition: (a), in hexane; (b), dry condition.

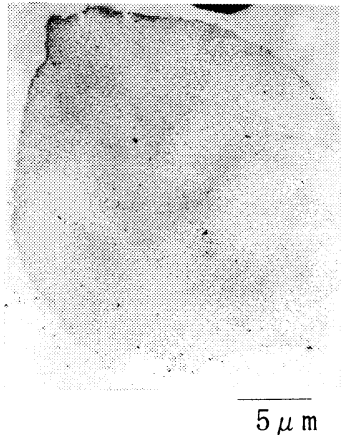

Cross section

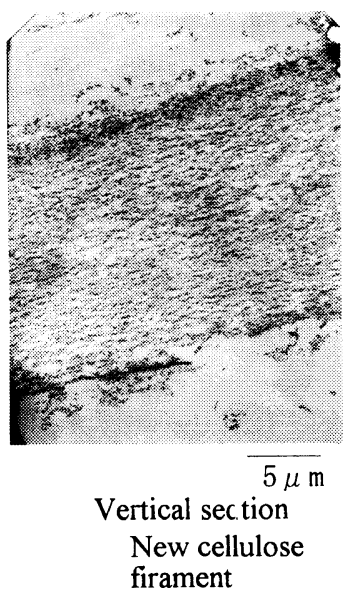

possibility that $\gamma_{\mathrm{TSC}}$ corresponds to $\beta_{\mathrm{a} 2}$.

\section{Morphological Characteristics of New Cellulose Fiber}

So far, the cross sectional morphological observation for regenerated cellulose fibers such as cuprammonium rayon and viscose rayon has been carried out by interference microscopic analysis and skin-core dyeing technology, revealing that viscose rayon has a clear skin-core two phase structure and cuprammonium rayon has 3 or 4 phase structure. ${ }^{37}$ However, the distribution of fibril structure and its orientation for the regenerated fibers has remained still as an unsolved problem. Although TEM observation on the ultra-thin section of fiber in the fiber axis direction is suitable for detection of micro-fibrillar structure, it is usual that the structural distribution including fibrillar structure could not be observed due to almost no density difference in the inner part of fiber in most cases. Then, the enzyme (cellulase) etching technology before TEM observation was applied in this study. The enzyme etching technology has been applied to determine the accessibility due to the difference in the higher order structure of fibers ${ }^{38}$ but the direct observation of TEM after enzyme etching has not been reported hithertofore.

Figure 8 shows TEM micrographs for various regenerated cellulose fibers used here. It is obvious from cross section and longitudinal section that new cellulose filament almost even structure having no morphological distribution in the fiber radius direction and is composed of short fibrils. Three phase morphology (skin phase in most outer layer, net work with no considerable fibril structure in the medium layer and the well-developed fibrillar structure in most inner layer) was observed for

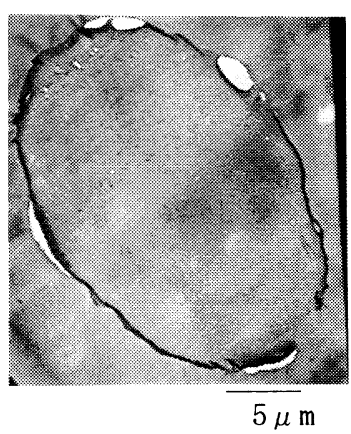

Cross section

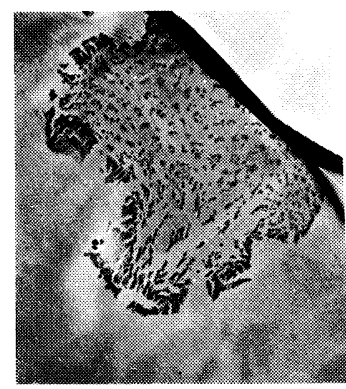

$5 \mu \mathrm{m}$

Cross section

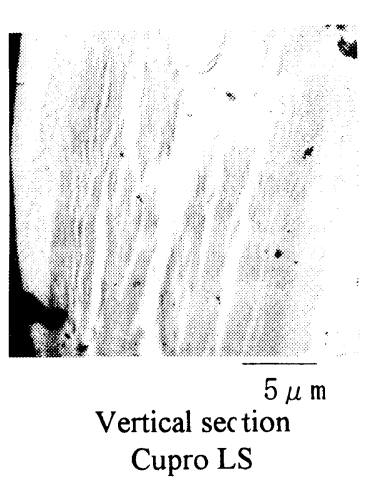

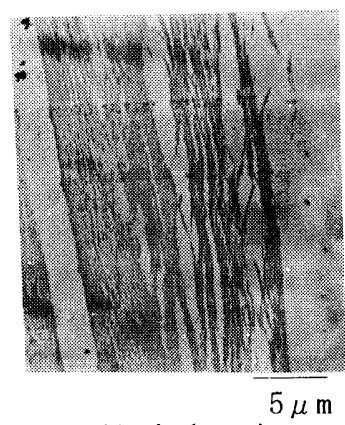

Vertical section Organic spun rayon

Figure 8. TEM micrographs of cross and vertical section of cellulose fibers after enzyme etching. 
Table IV. Mechanical properties of cellulose fibers

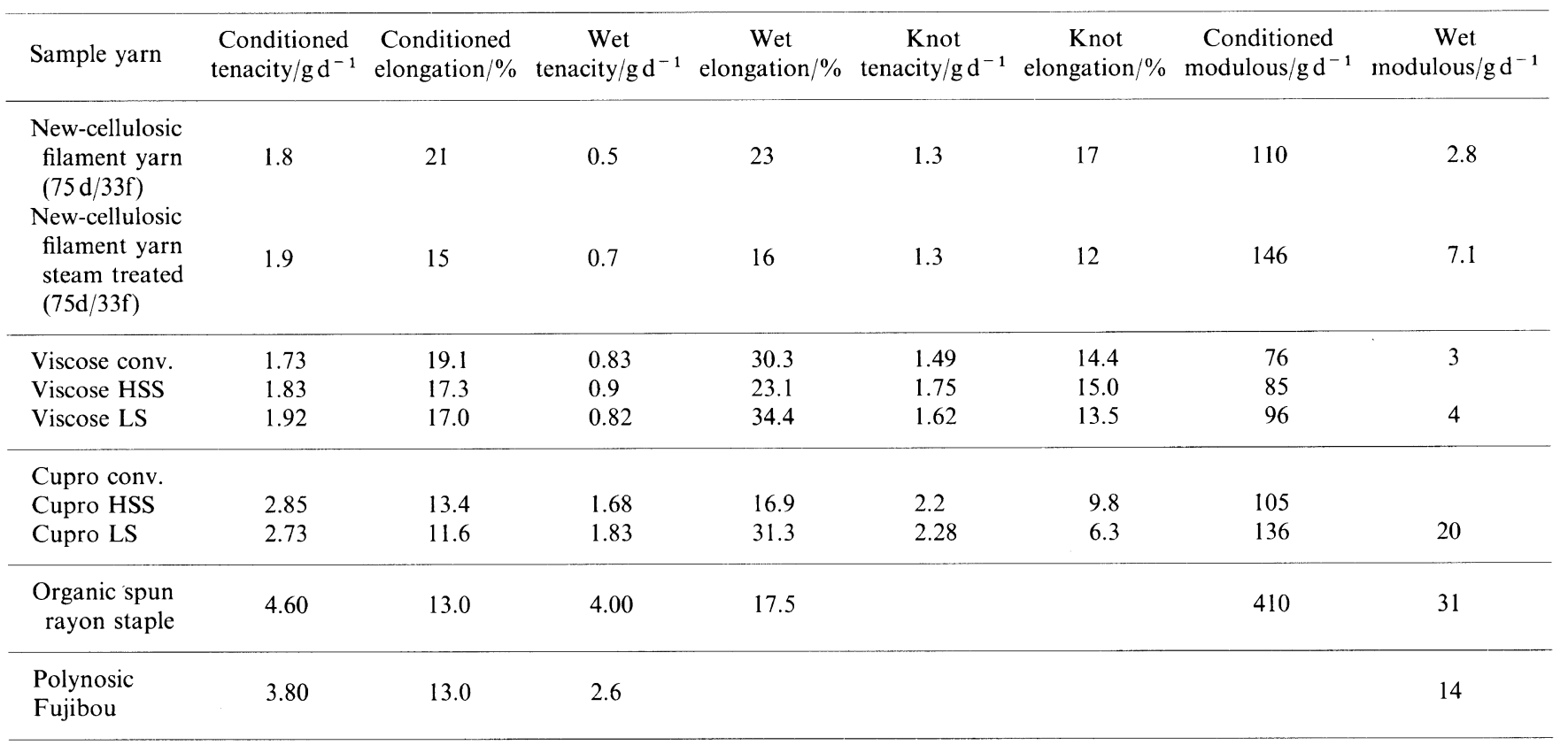

\begin{tabular}{|c|c|c|c|c|c|c|c|}
\hline Sample yarn & $\begin{array}{c}\text { Shrinkage in } \\
\text { boiling water } / \%\end{array}$ & Whiteness & Yellowness & Luster & $\begin{array}{c}\text { Swelling } \\
\text { capacity } / \%\end{array}$ & Fibrillation & $\begin{array}{c}\text { Dyestuff } \\
\text { absorption/\% }\end{array}$ \\
\hline $\begin{array}{l}\text { New-cellulosic } \\
\text { filament yarn } \\
(75 \mathrm{~d} / 33 \mathrm{f})\end{array}$ & 2.8 & 87.1 & 8.2 & 14.0 & 80 & 95 & 78.1 \\
\hline $\begin{array}{l}\text { New-cellulosic } \\
\text { filament yarn } \\
\text { steam treated } \\
(75 \mathrm{~d} / 33 \mathrm{f})\end{array}$ & 1.6 & 86.0 & 11.3 & 14.6 & 50 & 95 & 55.8 \\
\hline Viscose conv. & 2.5 & & 6.7 & 44.5 & 102 & 100 & 53.0 \\
\hline Viscose HSS & 1.6 & & 13.5 & 12.4 & 106 & 100 & \\
\hline Viscose LS & 6.3 & & 14.5 & 50.0 & 120 & 100 & \\
\hline $\begin{array}{l}\text { Cupro conv. } \\
\text { Cupro HSS }\end{array}$ & 0.4 & & 14.1 & & 88 & 85 & \\
\hline $\begin{array}{l}\text { Organic spun } \\
\text { rayon staple }\end{array}$ & 0.2 & & & & 65 & 50 & \\
\hline $\begin{array}{l}\text { Polynosic } \\
\text { Fujibou }\end{array}$ & & & & & 65 & 60 & \\
\hline
\end{tabular}

cuprammonium rayon. Note that for cuprammonium rayon the enzyme etching works most effectively inner part remaining the skin part, suggesting the rather low crystallinity of inner part. The skin-core structure, which is characterized as having numerous voids with different sizes but without fibrillar structure, was observed for viscose rayon, as has been pointed out. Organic spun rayon has similar even structure and morphology to that of new cellulose fiber but with well-developed fibrils. The reason for the fact that new cellulose and organic spun rayon have even one phase morphology and viscose and cuprammonium rayons have multi-phase morphology might reside in whether chemical structural change takes place or not during coagulation procedure.

\section{Mechanical and Topical Properties of New Cellulose Fiber and Its Woven Fabrics}

Table IV collects the above properties of new cellulose fiber in comparison with other commercial regenerated cellulose fibers. In the same table, these properties of the new cellulose fiber treated with steam are also collected. The steam treatment on new cellulose fiber resulted in the lowering in elongation, swelling capacity and dyestuff absorption and in the increasing in modulus, all of which are related to molecular ordering, as was pointed out before. New cellulose fiber shows almost similar tensile properties to viscose rayon. Its luster is preferable to that of viscose rayon, exhibiting far lower value. Dimensional stability of new cellulose is higher than that of viscose rayon, judged from swelling capacity and this tendency is more considerable for the stream-treated new cellulose of which swelling capacity is lower than all other regenerated cellulose fibers. The resistance to fibrillation, which is a key point leading to wide variety of end-usages, is also superior to other fibers, except for viscose rayon. 
Table V. Properties of plain weave fabrics

\begin{tabular}{|c|c|c|c|c|c|c|}
\hline \multirow[t]{2}{*}{ Sample } & \multirow[t]{2}{*}{$\begin{array}{l}\text { Resin } \\
\text { finish }\end{array}$} & \multirow{2}{*}{$\begin{array}{l}\text { Color fastness to } \\
\text { rubbing in wet } \\
\text { state }\end{array}$} & \multirow{2}{*}{$\begin{array}{c}\text { Color } \\
\text { fastness to } \\
\text { light }\end{array}$} & \multirow{2}{*}{$\begin{array}{l}\text { Surface } \\
\text { abrasion } \\
\text { resistance }\end{array}$} & \multirow{2}{*}{$\begin{array}{l}\text { Bending } \\
\text { resistance } \\
(\text { warp }) / \mathrm{cm}\end{array}$} & \multirow{2}{*}{$\begin{array}{c}\begin{array}{c}\text { Wrinkle } \\
\text { recovery }\end{array} \\
\%\end{array}$} \\
\hline & & & & & & \\
\hline New-cellulosic filament yarn $(75 \mathrm{~d} / 33 \mathrm{f})$ & 0 & $2-3$ & 5 & 2900 & 3.6 & 45 \\
\hline New-cellulosic filament yarn, steam treated $(75 d / 33 f)$ & $\mathrm{O}$ & $2-3$ & 4 & 3700 & 3.8 & 59 \\
\hline Viscose rayon $(75 \mathrm{~d} / 33 \mathrm{f})$ & O & $2-3$ & 5 & 3300 & 4.4 & 47 \\
\hline Cuprammonium rayon $(75 \mathrm{~d} / 54 \mathrm{f})$ & O & 3 & 5 & 2100 & 4.4 & 56 \\
\hline New-cellulosic filament yarn $(75 \mathrm{~d} / 33 \mathrm{f})$ & - & $1-2$ & 5 & 2100 & 3.7 & \\
\hline New-cellulosic filament yarn, steam treated $(75 d / 33 f)$ & - & $1-2$ & 4 & 5400 & 3.7 & \\
\hline Viscose rayon $(75 d / 33 f)$ & - & $1-2$ & 5 & 6000 & 4.2 & \\
\hline Cuprammonium rayon $(75 \mathrm{~d} / 54 \mathrm{f})$ & - & $1-2$ & 5 & 2600 & 4.3 & \\
\hline
\end{tabular}

Table $\mathrm{V}$ shows typical properties of woven fabrics made from new cellulose fibers with or without steam treatment in comparison with those from viscose and cuprammonium rayons. The table includes the results with or without resin finishing. The fabrics from the steam-treated new cellulose yarn without resin finishing gives some softness, compared with other commercial ones, and this tendency does not alter after resin finishing. Abrasion resistance of the fabrics from the steamtreated new cellulose is highest among fabrics tested here and is most hard to wrinkle. Color fastness of the new cellulose fabrics is in the same order as those others. Thus, new cellulose fiber was proved to have sufficient potentials for alternatives of the present commercial regenerated cellulose fiber, especially, viscose and cuprammonium rayon.

\section{REFERENCES}

1. C. Yamane, M. Saitoh, and K. Okajima, Sen-i Gakkaishi, 52, 310 (1996).

2. K. Kamide, K. Okajima, T. Matsui, and K. Kowsaka, Polym. J., 16, 857 (1984).

3. T. Yamashiki, T. Matsui, M. Saitoh, K. Okajima, and K. Kamide, Br. Polym. J., 22, 73 (1990).

4. K. Kamide, K. Okajima, and K. Kowsaka, Polym. J., 24, 71 (1992).

5. C. Yamane, M. Saitoh, and K. Okajima, Sen-i Gakkaishi, 52, 318 (1996).

6. C. Yamane, M. Saitoh, and K. Okajima, Sen-i Gakkaishi, 52, 369 (1996).

7. C. Yamane, M. Saitoh, and K. Okajima, Sen-i Gakkaishi, 52, 378 (1996).

8. C. Yamane, M. Saitoh, and K. Okajima, Proceedings, "the 1st Cellulose Conference, Japan," The Cellulose Society of Japan, Tokyo, 1994, p 183.

9. C. Yamane, Kobunshi (High Polymers Japan), 44, 670 (1995).

10. T. Yamashiki, M. Saitoh, K. Yasuda, K. Okajima, and K. Kamide, Cellulose Chem. Technol., 24, 237 (1990).

11. T. Yamashiki, T. Matsui, K. Kowsaka, M. Saitoh, K. Okajima, and K. Kamide, J. Appl. Polym. Sci., 44, 691 (1992).

12. P. Scherrer and D. Gottinger, Nachr., 2, 98 (1918).

13. K. Kowsaka, K. Kamide, and K. Okajima, Abstracts "Development in Cellosics \& Wood, Cellucon 88 Japan, Kyoto," The Society of Fiber Science and Technology, Japan, Tokyo, 1988, p 18.

14. D. Gagnaire, J. Polym. Sci., Polym. Chem. Ed., 18, 13 (1980).

15. M. Inamoto, I. Miyamoto, M. Iwata, and K. Okajima, Polym. $J .$, to be submitted.

16. T. Takahashi, Sen-i Gakkaishi, 25, 80 (1969).

17. T. Hongoh, C. Yamane, M. Saitoh, and K. Okajima, Polym. J., 28, 1077 (1996)

18. D. Loubinoux and S. Chaunis, Text. Res. J., 57, 61 (1987).

19. E. Thiele, DRP, 154507, 157157 (1901).

20. S. Manabe, M. Iwata, and K. Kamide, Polym. J., 18, 1 (1986).

21. S. Manabe and R. Fujioka, Polym. J., to be submitted.

22. S. A. Bradley and S. H. Carr, J. Polym. Sci., Polym. Phys. Ed., 14, 111 (1976).

23. J. Schelten B. G. H. Ballard, G. D. Wignall, and G. Longman, Polymer, 17, 751 (1976); ibid., 18, 1111 (1977).

24. M. Imai, K. Mori, T. Mizukami, K. Kazi, and T. Kanaya, Polymer, 33, 4451 (1992).

25. M. Imai, Macromolecules, 27, 7103 (1994).

26. K. Kaji, Gekkan Physics, 4, 588, (1983).

27. A. N. J. Heyn, J. Am. Chem. Soc., 71, 1873 (1949).

28. P. H. Hermans, J. Polym. Sci., 6, $433(19)$ ).

29. W. O. Statton, J. Polym. Sci., 22, 385 (1956).

30. J. Hayashi, J. Masuda, and Y. Watanabe, Nippon Kagaku Kaishi, 5, 948 (1974)

31. P. H. Hermans, J. Polym. Sci., 4, 145 (1949).

32. The Society of Thermal Analysis Japan, "Netubunseki no Kisoto Ouyou," Kagakugijyutusya, Tokyo, 1985, p 130.

33. A. Sawatari, "Study in Electrical and Electronic Engineering," Vol. 2, Elsevier, Amsterdam, 1979, p 347.

34. M. Fushtani, Zairyou, 32, (359), 887 (1983).

35. P. Pissis, A. Anagnostopoulou-Konsta, L. Apekis, D. DaoukakiDiamanti, and C. Christodoulides, J. Non-Crystalline Solids, 131-133, 1174 (1991).

36. H. Eyring, J. Chem. Phys., 3, 107 (1935).

37. The Textile Machinery Society of Japan, Ed., "Sen-I Kougaku (II)," The Textile Machinery Society of Japan, Osaka, 1983, p 215.

38. M. Kawano, K. Mituishi, and T. Takeuti, Sen-i Gakkaishi, 51, 1 (1995). 